\title{
Stapes surgery for patients with mixed hearing loss
}

\author{
Jacob J Rapier, Georgia E Theodoraki, Joseph G Manjaly, Robert Nash and Jeremy A Lavy \\ Royal National Throat, Nose and Ear Hospital
}

\section{Aim}

To determine the benefit of stapes surgery for otosclerosis in patients with mixed hearing loss and pre surgical average bone conduction threshold $(\mathrm{BC})>30 \mathrm{~dB}$.

\section{Background}

Otosclerosis classically causes a conductive hearing loss picture, with elevated air conduction (AC) thresholds and a raised air-bone gap (ABG). In some patients there is an apparent sensorineural component in their hearing loss, demonstrated by increased bone conduction (BC) thresholds. The Carhart effect in otosclerosis can give a false positive increase in $\mathrm{BC}$ thresholds across all frequencies but particularly at $2 \mathrm{kHz}$. Current treatment options for otosclerosis patients are: hearing aid use, mixed stapes surgery with implanted hearing, aid and stapes surgery alone. Patients with $\mathrm{BC}$ of $>30 \mathrm{~dB}$ are traditionally not considered to be good candidates for stapes surgery. We therefore aimed to address two questions in studying this subgroup of patients with $B C>30 \mathrm{~dB}$ :

1) Is the high $B C$ threshold a false positive result caused by the Carhart effect?

2) Are patients with $B C$ threshold $>30 \mathrm{~dB}$ good candidates for stapes surgery to avoid hearing aid use?

\section{Methods}

Retrospective review of 121 patients with otosclerosis and average BC thresholds $>30 \mathrm{~dB}$ undergoing stapedotomy and SMART $360^{\circ}$ prosthesis placement with a single surgeon (between July 2013 and July 2017).

3 Outcomes were assessed:

1) Audiometry results (pre and post surgery for 121 patients)

2) Quality of life using the Glasgow Benefit Inventory (GBI) for 87 of these patients

3) Hours of hearing aid use pre and post surgery for 87 patients

\section{Life Quality Results}

- $84 \%$ of patients had a significant increase in their GBI scale $(>30)$

- $5(5.7 \%)$ patients saw a decrease in their QoL points

\section{Hours of hearing aid use Results}

- $49(56 \%)$ patients went from using a hearing aid to not needing one

- 2 patients went from never needing a hearing aid, to using one

\section{Hearing aid use pre- and post-operative}

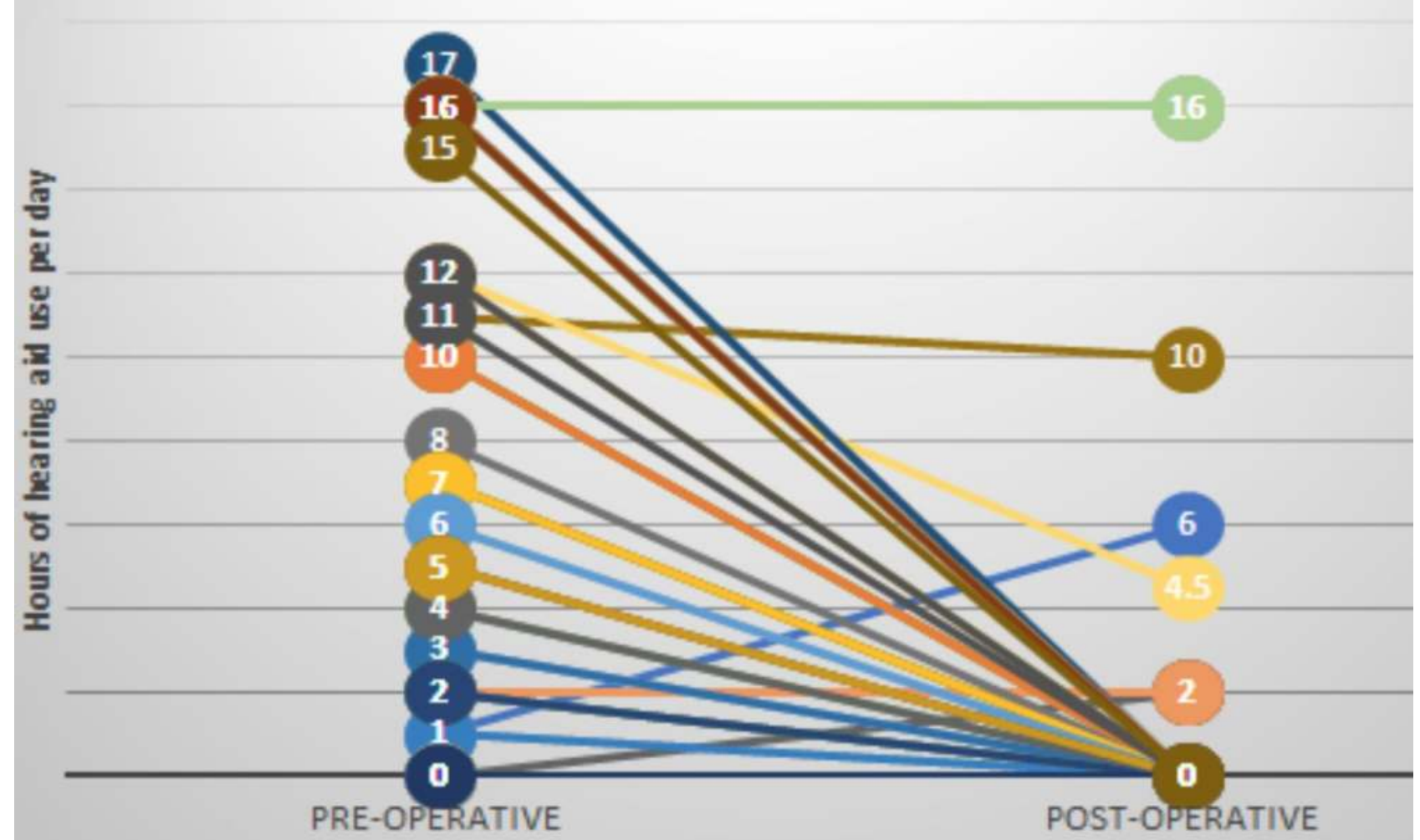

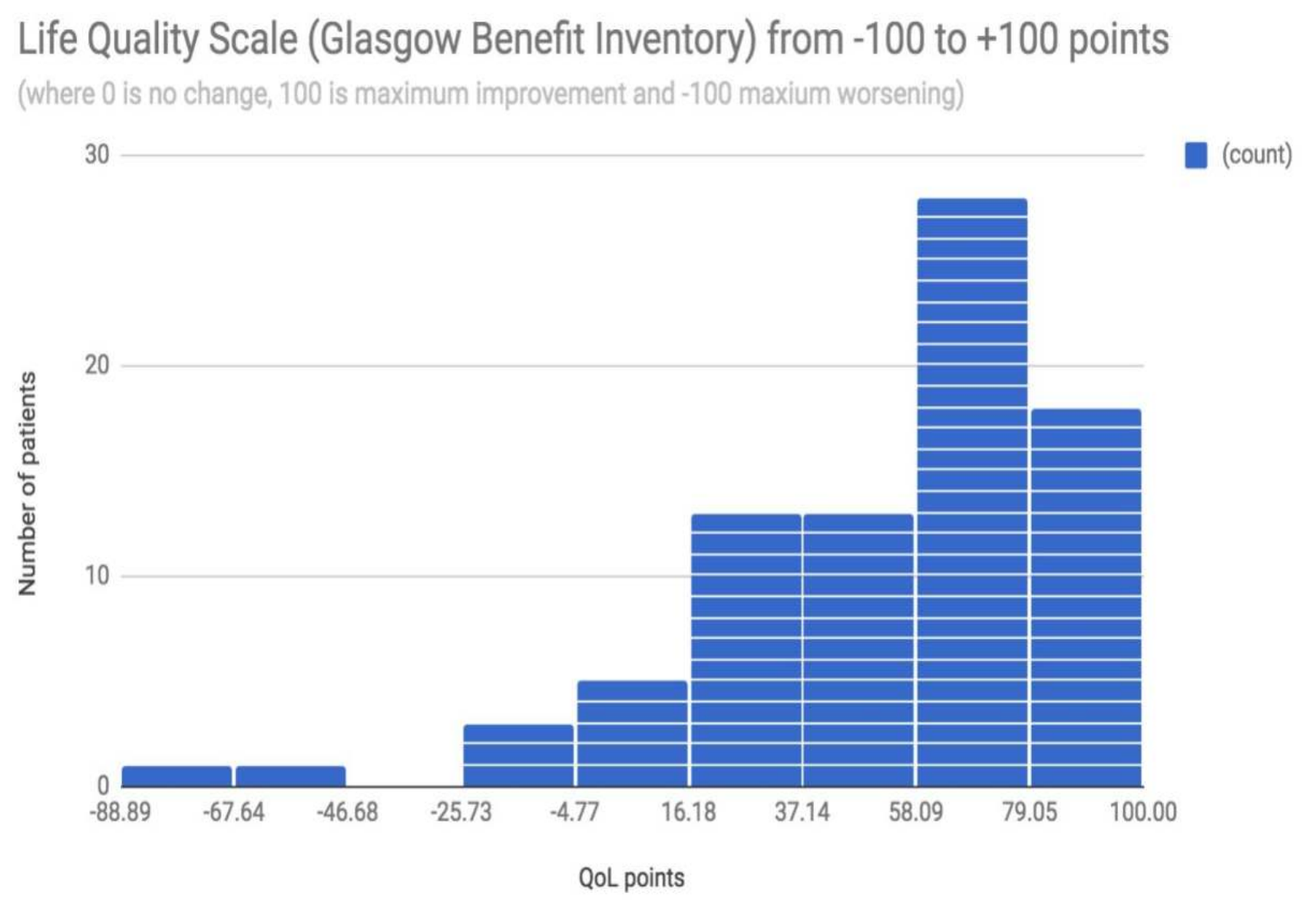

\section{Audiometry Results}

- Air Bone Gap

- Improved in $95.04 \%(n=115)$ of patients

- Significantly closed (to $<10 \mathrm{~dB}$ ) in $79.34 \% \quad(n=96)$ of patients. Average ABG closure was $20.8 \mathrm{~dB}$.

- Air conduction - Overclosure

- $57.02 \%(n=69)$ of patients achieved a post-surgical AC better than their pre-surgical BC (Overclosed). In theory, this would have been impossible, unless the pre-surgical BC was falsely increased, due to the Carhart effect.

- The highest percentage of overclosure $(67.7 \%, n=82)$ was seen at $2 \mathrm{kHz}$, which aligns with the Carhart notch.

- Bone conduction

- $72.5 \%$ of patients had an improvement in their BC

- $64 \%$ improved their BC thresholds to less than $30 \mathrm{~dB}$ after surgery - unexpected improvement in sensorineural hearing

\begin{tabular}{|c|c|c|c|c|c|c|}
\hline $\begin{array}{l}\text { Frequency } \\
\text { and dB }\end{array}$ & Average & $0.5 \mathrm{kHz}$ & $1 \mathrm{kHz}$ & $2 \mathrm{kHz}$ & $3 \mathrm{kHz}$ & $4 \mathrm{kHz}$ \\
\hline post $B C$ & 28.2 & 22.9 & 24.8 & 34.3 & 31.0 & 28.6 \\
\hline (post-pre BC) & -6 & -4 & -6 & -9 & -6 & -12 \\
\hline pre $B C$ & 34.3 & 26.7 & 31.1 & 42.9 & 36.7 & 30.2 \\
\hline (postAC-preBC) & 0 & +5 & 1 & -6 & 0 & +11 \\
\hline post $A C$ & 34.3 & 31.8 & 32.1 & 36.6 & 36.7 & 40.8 \\
\hline (post - pre AC) & -27 & -33 & -30 & -23 & -23 & -21 \\
\hline pre $\mathrm{AC}$ & 61.5 & 64.6 & 62.4 & 59.4 & 59.4 & 62.1 \\
\hline
\end{tabular}

\section{Conclusion}

When assessing suitability for surgery, surgeons should consider that pre-operative bone conduction thresholds may be a poor indicator of the true cochlear reserve. As a result there is a potential for improvement in both air and bone conduction thresholds in patients who would otherwise would have been classified as poor candidates for stapes surgery. We would therfore recommend that a stpedotomy is carried out before an implanted hearing aid is fitted in otosclerosis patients with apparent poor cochlear r reserve. 